\title{
P-1398 - BURNOUT AND ENGAGEMENT IN PORTUGUESE MALE MILITARY OFFICERS
}

C.Queirós, E.Teixeira, A.J.Marques

Laboratório de Reabilitação Psicossocial, Faculdade de Psicologia e de Ciências da Educação da Universidade do Porto e Escola Superior de Tecnologia da Saúde do Instituto Politécnico do Porto, Porto, Portugal

Introduction: Occupational stress is a contemporary concern due to its negative consequences in workers, especially when chronic, since it can provoke burnout (Freudenberger, 1974; Maslach, 1976). However, engagement is being identified as a possible protector of burnout and occupational stress (Schaufeli et al., 2002). Military officers have a dangerous and stressful activity, factor that is enhancing studies on burnout and engagement in this group (Alarcon et al., 2010; Chambel \& Cruz, 2010; Ivie \& Garland, 2011).

Aims: To identify burnout and engagement on Portuguese military officers.

Methods: Data were collected using MBI (Maslach \& Jackson, 1997) and UWES (Schaufeli \& Bakker, 2003) Portuguese versions (Marques-Pinto, 2009) applied to 61 male Portuguese military officers, aged 19-51 years $(M=28.4 \mathrm{SD}=9.2)$, with an average of 8.1 years of job experience, $30 \%$ married, 23\% having children, and 74\% working more than 35 hours per week.

Results: The sample shows low emotional exhaustion ( $\mathrm{M}=1.6$ in a Likert scale $0-6$ points) and cynism $(\mathrm{M}=1.2)$, and high professional accomplishment $(\mathrm{M}=4.3)$, dedication $(\mathrm{M}=4.2)$, absorption $(\mathrm{M}=3.7)$, and vigour $(\mathrm{M}=3.5)$. Burnout was negatively correlated with engagement, and vigour negatively predicts emotional exhaustion $(\beta=-.362, p=.004)$ and depersonalization $(\beta=-.315, p$ $=.014)$, and positively predicts personal accomplishment $(\beta=.604, p=.000)$.

Conclusions: Despite low burnout, military officers are vulnerable to occupational stress. However, engagement is a protector, especially vigour, allowing professionals to be dedicated and absorbed by their activity. For this reason, it is very important to develop studies with the aim of understanding how military institution can influence the health of their professionals. 